\title{
Christopher Brumfit Ph.D./Ed.D. Thesis Award 2009
}

\section{Sponsored by Cambridge University Press and promoted by Language Teaching}

Aim To recognise doctoral thesis research that makes a significant and original contribution to the field of second language teaching and learning broadly understood.

Award Cambridge University Press books to the value of $£, 500$.

Eligibility To be considered for the award:

- The candidate's institution must have accepted the thesis within two years before the date of the award application.

- The research must have been completed as part of the requirements for a doctoral degree or its equivalent at a university.

- Although the thesis under consideration must be in English, the research may be related to work concerning any second language.

Application process In the first instance, applicants must submit the following:

- A summary of the thesis, not to exceed 17 double-spaced pages, with references, and a 150-word abstract of the thesis. Care should be taken in drafting the summary so that the referees are provided with as detailed a report as possible on the work undertaken. The summary should include a brief description of the theoretical background of the research and specify the research questions, the research methods (including data analyses) used and why these were chosen, the results, and implications of these outcomes. It should also make clear the perceived contribution of the work undertaken to the field of second language acquisition and/or foreign language teaching and learning.

- Proof of acceptance of the thesis by the candidate's university.

Only electronic applications are accepted.

Evaluation criteria The following aspects of the theses will be considered by the panel:

- Scholarly or professional significance to the field of second or foreign language

- Originality and creativity

- Quality of presentation

\section{Dates}

30 November 2009: Deadline for receipt of summary and abstract and official proof of thesis acceptance

15 February 2010: Call for electronic submission of theses of finalists

3 March 2010: Deadline for receipt of theses

1 August 2010: Announcement of award winner by the Editorial Board of Language Teaching

\section{Further information and application}

Dr Graeme Porte, Editor Language Teaching

Email: gporte@gmail.com 